drug treatment and the patient's illness but it would also render such treatment more acceptable to those patients and doctors who are more impressed by the results of objective diagnostic tests than by psychiatric advice alone. Finally, the improvement in nosology should have positive effects on research.

\footnotetext{
${ }^{1}$ Ettigi PG, Brown GM. Psychoneuroendocrinology of affective disorder: an overview. Am $\mathcal{F}$ Psychiatry 1977;134:493-501.

2 Sachar EJ, Asnis G, Halbreich U, Nathan RS, Halpern F. Recent studies in the neuroendocrinology of major depressive disorders. Advances in psychoneuroendocrinology. Psychiatric Clinics of North America 1980;3:313-26.

${ }^{3}$ Kendell RE. The role of diagnosis in psychiatry. Oxford: Blackwell Scientific Publications, 1975.

4 Carroll BS. Neuroendocrine dysfunction in psychiatric disorders. In: Lipton MA, DiMascio A, Killam KF, eds. Psychopharmacology. $A$ generation of progress. New York: Raven Press, 1978:487-97.

5 Spitzer RL, Endicott J, Robins E. Research diagnostic criteria. 3rd ed. New York: New York State Division of Mental Health, Biometrics Research, 1977.

6 Gold MS, Pottash ALC, Extein I, Sweeney DR. Diagnosis of depression in the 1980s. FAMA $1981 ; \mathbf{2 4 5}: 1562-4$.

7 Gold MS, Pottash ALC, Ryan N, Sweeney DR, Davies RK, Martin DM. TRH-induced TSH response in unipolar, bipolar and secondary depressions: possible utility in clinical assessment and differential diagnosis. Psychoneuroendocrinology 1980;5:147-55.

${ }^{8}$ Goldberg IK. Dexamethasone suppression test as indicator of safe with-
} drawal of antidepressant therapy. Lancet 1980;i:376.

\section{Primary biliary cirrhosis}

For all its rarity, primary biliary cirrhosis fascinates physicians because of its enigmatic origin, curious clinical picture, and bizarre hepatic lesion. Recent interest has centred on community studies of the disease and its serological marker the antimitochondrial antibody, and on the possibility of treatment by D-penicillamine. Participants at a recent workshop arranged by D R Triger at Sheffield spent much of the time discussing these two aspects.

Last year Triger $^{1}$ reported that nearly $90^{\circ}{ }_{0}$ of his patients came from an area of Sheffield that had only $40 \%$ of the population and was supplied by one particular reservoir. Moreover, the disease was commoner than expected, with an incidence of 5.8 per million and a point prevalence (number of cases in the community at a particular date) of 59 per million. Other speakers gave figures of 8.4 and 40 for Tayside, 6.9 and 50 for Southampton, 12.7 and 83 for the Glasgow area, and 6.0 and 47 for Newcastle upon Tyne. No one so far had found any evidence of clustering to match the Sheffield experience, and Triger had been unable to implicate an environmental factor in the water supply.

One of the difficulties in investigating primary biliary cirrhosis is the variety of pathological changes in the liver. Professor Peter Scheuer characterised the four stages of damage ${ }^{2}$ -florid bile-duct lesions, ductular proliferation, scarring (septal fibrosis and bridging), and cirrhosis-but emphasised that they were uneven and evolved at different speeds in different parts of the liver. Staging, he said, should be based on the most severe lesion present. Antimitochondrial antibodies are present in more than $95 \%$ of patients, ${ }^{3}$ but several speakers pointed out the need for standardisation of assay methods and for agreement on what constitutes a positive titre. This is particularly important in community surveys, where a few apparently healthy people are found to be positive for antimitochondrial antibody; a proportion of these can be shown to have the histological changes of primary biliary cirrhosis if subjected to liver biopsy. ${ }^{4}$

The importance of a firm diagnosis and proper staging is underlined by the possibility of treatment. Until recently little could be done except for relieving the intense itching by cholestyramine, and trying to prevent the demineralisation of bones from malabsorption of calcium and vitamin $\mathrm{D}$ resulting from chronic obstructive jaundice. Treatment with D-penicillamine was originally considered because of its chelating properties $^{5}$ : in the late stages of the disease accumulation of copper due to cholestasis reaches levels comparable with those seen in Wilson's disease. The drug may also have immunological and antifibrotic effects. At the Sheffield meeting Epstein reported guidelines for the treatment of primary biliary cirrhosis based on experience in the Royal Free Hospital trial. ${ }^{6}$ A starting dose of $150 \mathrm{mg}$ D-penicillamine daily is built up by monthly increments to $600 \mathrm{mg}$ while a careful watch is kept for side effects, such as rashes, neutropenia, and proteinuria. Little benefit is discernible up to 18 months, but thereafter survival is improved in patients with late-stage disease. While some improvement in liver function tests and histological damage appears when patients so treated are compared with controls, these procedures have not, unfortunately, proved of help in monitoring responses in individual patients. Symptomless patients and those with stage I and stage II disease need not be treated, as the prognosis is generally good in these groups; but ideally they should have a liver biopsy performed every year or so to detect any deterioration.

1 Triger DR. Primary biliary cirrhosis: an epidemiological study. Br Med $\mathcal{Y}$ $1980 ; 281: 772-5$

- MacSween RN. Primary biliary cirrhosis. In: MacSween RN, Anthony A, Scheuer PJ, eds. Pathology of the liver. Edinburgh: Churchill, 1979 306-14.

3 Munoz LE, Thomas HC, Scheuer PJ, Doniach D, Sherlock S. Is mitochondrial antibody diagnostic of primary biliary cirrhosis ? Gut $1981 ; \mathbf{2 2}$ 136-40.

' James O, Macklon AF, Watson AJ. Primary biliary cirrhosis-a revised clinical spectrum. Lancet $1981 ; \mathrm{i}: 1278-81$.

5 Jain S, Scheuer PJ, Samourian S, McGee JO'D, Sherlock S. A controlled trial of D-penicillamine therapy in primary biliary cirrhosis. Lancet $1977 ; \mathrm{i}: 831-4$.

${ }^{6}$ Epstein O, Jain S, Lee RG, et al. D-penicillamine treatment improves survival in primary biliary cirrhosis. Lancet $1981 ; 1: 1275-7$.

\section{Haemolytic disease of the newborn due to antibodies other than rhesus anti-D}

Perinatal mortality from haemolytic disease has fallen dramatically in the past 10 years. Stillbirths and neonatal deaths from this condition are almost always associated with alloimmunisation of the mother to the rhesus antigen $\mathrm{D}$, and the decline has been due to two main factors. One is the smaller size of families, stillbirth from haemolytic disease tending to occur in later pregnancies. The other, and more important, is that since about 1968 alloimmunisation to $\mathrm{D}$ has been largely prevented by giving anti-D immunoglobulin to the $\mathrm{Rh}$ negative mother immediately after delivery of an Rh-positive baby. Such prophylactic treatment does not, however, prevent alloimmunisation by antigens other than $\mathrm{D}$, so that cases of haemolytic disease of the newborn from antibodies other than rhesus anti-D are becoming proportionally more important.

A survey by Giblett ${ }^{1}$ carried out before prophylactic treatment was introduced found that $7^{\circ} \%$ of 420 cases of haemolytic disease in Washington were caused by antibodies other than anti-D or anti-C + D. Almost all of these were in babies born to $\mathrm{Rh}$-positive mothers, and in about half the antibodies 
responsible were anti-c (or anti-c E). Fraser and Tovey ${ }^{2}$ reported similar findings from south-west England with 1099 cases of haemolytic disease investigated between 1966 and 1968; of these, $70\left(60^{\prime \prime}{ }_{11}\right)$ were due to anti-c. By 1974 prophylactic treatment had cut the total number of affected babies born in the region to 106 and the proportion caused by anti-c had risen to $12^{\prime}{ }_{1}$. In about one-third of cases due to anti-c Fraser and Tovey found that the mother had received a blood transfusion before pregnancy.

As a result of these and other surveys Hardy and Napier ${ }^{3}$ have published a comprehensive analysis of $733 \mathrm{Rh}$-positive women with red cell antibodies found during antenatal testing in South and mid-Wales of more than 380000 expectant mothers over the 30 years 1948-78. In $81^{\circ}$ "of the immunised $\mathrm{Rh}$-positive mothers the antibodies could be classed as antirhesus, predominantly anti-E, anti-c, or anti-c $!$ E. Of 136 with antibodies outside the rhesus system, most were anti-Kell $\left(71^{\prime \prime}{ }_{11}\right)$ or anti-Fy" $\left(13^{\prime \prime}{ }^{\prime}\right)$. Transfusion history differed in those mothers who had developed anti-rhesus antibodies and those with antibodies outside the rhesus system: $71^{\prime \prime}$ "of those with non-rhesus antibodies gave a history of previous blood transfusion, compared with $21^{\circ}{ }^{\circ}$ when the antibodies were antirhesus.

The incidence of haemolytic disease in the babies born to mothers also differed in these two groups. When the maternal antibody was anti-rhesus half the babies were affected compared with only a quarter when the antibodies were nonrhesus. Perinatal mortality was the same in both groups $\left(2 \cdot 5-3 \cdot 0^{\prime \prime}{ }^{\prime}\right)$, though when the fetomaternal incompatibility was due to a rhesus antigen $15^{\prime \prime}$ " of affected babies required transfusion, compared with $6^{\prime \prime}{ }_{1}$, when the antibody was non-rhesus. In a similar report from Australia ${ }^{4}$ Beal found that babies born to $\mathrm{Rh}$-positive women and affected with haemolytic disease rarely required transfusion unless the antibodies responsible were anti-rhesus or anti-Kell. Hardy and Napier's survey ${ }^{3}$ confirms the generally held view that babies born to $\mathrm{Rh}$ negative mothers with anti-D are more severely affected, perinatal deaths being more than three times as great $\left(11^{\prime \prime}{ }_{0}\right)$ and the need for treatment by transfusion $40-45^{\prime \prime}$ ".

Hardy and Napier's findings ${ }^{3}$ underline the importance of rhesus anti-c as a cause of haemolytic disease of the newborn as seen today. Almost 90" "of c-positive infants born to women with anti-c in South and mid-Wales had evidence of hacmolytic disease as judged by a positive direct antiglobulin test, and $20^{\prime \prime}$ " needed transfusion. Neither the overall frequency of the disease nor its severity in affected babies is sufficient, however, to warrant attempted prophylaxis by the injection of cnegative mothers with anti-c immunoglobulin. Clarke and Whitficld" found that a total of 85 babies died from haemolytic disease of the newborn in England and Wales in 1978 but that only three had been born to Rh-positive women. Fraser and Tovey ${ }^{2}$ recommend $c$ typing of all premenopausal women being given blood transfusions and the issue of c-negative and Kell-negative blood for emergency transfusion to patients known to be Rh-positive. Since nearly all c-negative donor bloods lack the $\mathrm{E}$ antigen these are practicable steps which would minimise the formation of anti-c, anti-E, and anti-Kell antibodies-the predominant causes of haemolytic disease when an Rh-positive mother gives a history of blood transfusion. When the affected baby requires treatment by exchange or intrauterine transfusion, the blood for transfusion must not react with the mother's antibodies-that is, cnegative blood is required when the causative antibody is anti-c or Kell-negative if anti-Kell.

Routine antenatal examination for irregular blood group antibodies is of importance not only to identify the few Rhpositive mothers who are carrying a baby affected with haemolytic disease but also to ensure that compatible blood will be available should the mother herself require a blood transfusion. Clearly such antibodies are best detected and identified at a time other than in a clinical emergency. Blood samples from all expectant mothers should be screened for antibodies early in the pregnancy. When a woman is Rh-positive and no irregular antibodies are detected further testing later in the pregnancy will be indicated when there is a history of blood transfusion. In all such cases repeat tests for irregular blood group antibodies should be made on samples collected at the 28th and 34th weeks of pregnancy.

1 Giblett ER. Blood group antibodies causing hemolytic disease of the newborn. Clin Obstet Gynecol 1964;7:1044-55.

${ }^{2}$ Fraser ID, Tovey GH. Observations on $\mathrm{Rh}$ iso-immunisation: past, present and future. Clin Haematol 1976;5:149-63.

${ }^{3}$ Hardy J, Napier JAF. Red cell antibodies detected in antenatal tests on rhesus positive women in South and mid-Wales, 1948-78. Br F Obstet Gynaecol $1981 ; 88: 91-100$.

1 Beal RW. Non-rhesus (D) blood group isoimmunization in obstetrics. Clin ()bstet Gynecol 1979;6:493-508.

s Clarke C, Whitfield AGW. Deaths from rhesus haemolytic disease in England and Wales in 1978: accuracy of records and assessment of antiD prophylaxis. $\mathrm{Br} \mathrm{Medf1980;281:781-2.}$

\section{Teratogenic risks of antiepileptic drugs}

The incidence of congenital malformations in the children of mothers with epilepsy is estimated to be two to three times the usual rate. ${ }^{2}$ The common major anomalies include cleft lip and palate and congenital heart lesions; malformations of the skeleton, central nervous system, and gastrointestinal tract also occur. The offspring of epileptic mothers have also been reported to have a lower birth weight and a higher perinatal mortality rate. ${ }^{3}$ The increased frequency of malformations in children born to epileptic mothers has been attributed to the teratogenic effects of antiepileptic drugs, an association supported by animal experiments. ${ }^{4}$ Phenytoin in particular but also phenobarbitone and primidone have been incriminated; sodium valproate is also teratogenic in animals but apparently carries little risk in man, though it cannot be exonerated completely as it has not been used as long as the others. A report from Finland ${ }^{4 a}$ shows that the mean head circumference of infants of epileptic mothers exposed to carbamazepine and drug combinations that included phenobarbitone and primidone were smaller than in controls. Most of the individual values, however, were still normal; and it has not been established that a subtle reduction in head size reflects a drug effect on the fetal brain. Reports of a "fetal trimethadione syndrome" suggests that the diones carry a high risk and should be avoided in pregnancy ${ }^{5}{ }^{6}$; in any case they have been superseded in Britain for the treatment of petit mal by ethosuximide and sodium valproate.

One controversial aspect of this problem is the so-called "fetal hydantoin syndrome." The features described are craniofacial and distal limb dysmorphosis, ${ }^{7-11}$ including a broad low nasal bridge, epicanthic folds, short upturned nose, hypertelorism, ocular abnormalities, prominent and slightly malformed or low set ears, wide mouth with prominent lips, and variations in the size and shape of the head; while hypoplasia of the distal phalanges and nails with irregular ossification produces short, narrow, and misshapen ends to fingers and 